Article

\title{
Autumnal Beach Litter Identification by Mean of Using Ground-Based IR Thermography
}

\author{
Cosimo Cagnazzo ${ }^{1, *(\mathbb{D})}$, Ettore Potente ${ }^{1} \mathbb{D}$, Hervé Regnauld $^{2}$, Sabino Rosato ${ }^{3}$ and Giuseppe Mastronuzzi $^{1}$ \\ 1 Department of Earth and Geo-Environmental Science, University of Bari, 70121 Bari, Italy; \\ ettore.potente@uniba.it (E.P.); giuseppe.mastronuzzi@uniba.it (G.M.) \\ 2 Littoral, Environnement, Télédétection, Géomatique, University of Rennes 2, 35043 Rennes, France; \\ herve.regnauld@univ-rennes2.fr \\ 3 Serveco Srl, 74020 Montemesola, Italy; s.rosato@serveco.it \\ * Correspondence: cosimo.cagnazzo@uniba.it
}

check for updates

Citation: Cagnazzo, C.; Potente, E.; Regnauld, H.; Rosato, S.;

Mastronuzzi, G. Autumnal Beach Litter Identification by Mean of Using Ground-Based IR Thermography. Environments 2021, 8, 37. https:// doi.org/10.3390/environments8050037

Academic Editor: Sílvia C. Goncalves

Received: 22 March 2021

Accepted: 22 April 2021

Published: 24 April 2021

Publisher's Note: MDPI stays neutral with regard to jurisdictional claims in published maps and institutional affiliations.

Copyright: (c) 2021 by the authors. Licensee MDPI, Basel, Switzerland. This article is an open access article distributed under the terms and conditions of the Creative Commons Attribution (CC BY) license (https:// creativecommons.org/licenses/by/ $4.0 /)$.

\begin{abstract}
The progress of scientific research and technological innovation are contributing to an increase in the use of rapid systems for monitoring and identifying geo-environmental processes related to natural and/or anthropogenic activities. The aim of this study is identifying autumnal beach litter using ground-based IR thermography. Starting from quarterly autumn monitoring data of air temperature and sandy soil surface temperature, an empirical equation between the two environmental matrices (air and sandy soil) is obtained. This will allow the calculation of the sandy soil surface temperature knowing only the air temperature. Therefore, it will be possible to know in advance the thermal response of the sandy soil, thus creating a thermal blank of the beach. Using an IR thermal camera, it is possible for a quicker identification of thermal anomalies of the coastal area potentially connected to the presence of pollution due to the anthropogenic origin (particularly plastic material). The test area is located in the area of the Coastal Dunes Regional Natural Park of Ostuni-Fasano in Apulia (southern Italy).
\end{abstract}

Keywords: beach litter; infrared thermography; UAV; UGV; environmental monitoring; coastal pollution

\section{Introduction}

Among the atmospheric and non-atmospheric parameters that influence the properties of the climate system, temperature is a very relevant parameter in all the chemical, physical and biological processes that affect the soil formation and its persistence in a natural environment. Considering the same source of thermal radiation, each material is heated differently according to its chemical-physical characteristics. Scientific research and technological innovation have developed new methodologies (IR thermography) and new investigation tools (thermal cameras) based on the use of temperature for the identification of different materials, such as sandy soil. IR thermography allows for detecting and quantifying the infrared energy emitted by any object above absolute zero temperature $\left(-273.14^{\circ} \mathrm{C}\right)$.

Since every object characterized by a temperature above absolute zero emits thermal energy, it can be identified through infrared thermography. Thermal cameras allow for quick and remote collection of a large amount of data.

Over the last few years, the use of thermography has become widespread in various fields such as: research and development, quality and process control, healthcare, construction, industry and the mechanical field [1-4]. In the environmental monitoring field, thermography had a remarkable development, especially in wildfire detection [5], while is only a first approach for flora and vegetation habitat monitoring, and sometimes also for wildfauna, which necessarily require observations and confirmations directly in the field. 
Moreover, the growing anthropogenic impact on the natural coastal environment is causing a significant increase in coastal pollution [6] and spills of chemical products in the marine environment [7]. The need to identify the areas affected by such events is affirming the use of thermography as a new technique, complementary to other traditional methodologies [8-10].

IR thermal cameras are also installed on aerial (UAV) and terrestrial (UGV) platforms, resulting in effective equipment in terms of time efficiency and timeliness [11-16].

The aim of this study is identifying autumnal beach litter using ground-based IR thermography. Starting from statistical analysis results of monitoring data collected by two air temperature and sandy-soil temperature sensors, installed in the Coastal Dunes Regional Natural Park (Ostuni-Fasano, Italy) (Figure 1), an empirical relation between the environmental matrices (air and sandy soil) will be found. This will allow to estimate the sandy-soil surface temperature knowing only the air temperature.
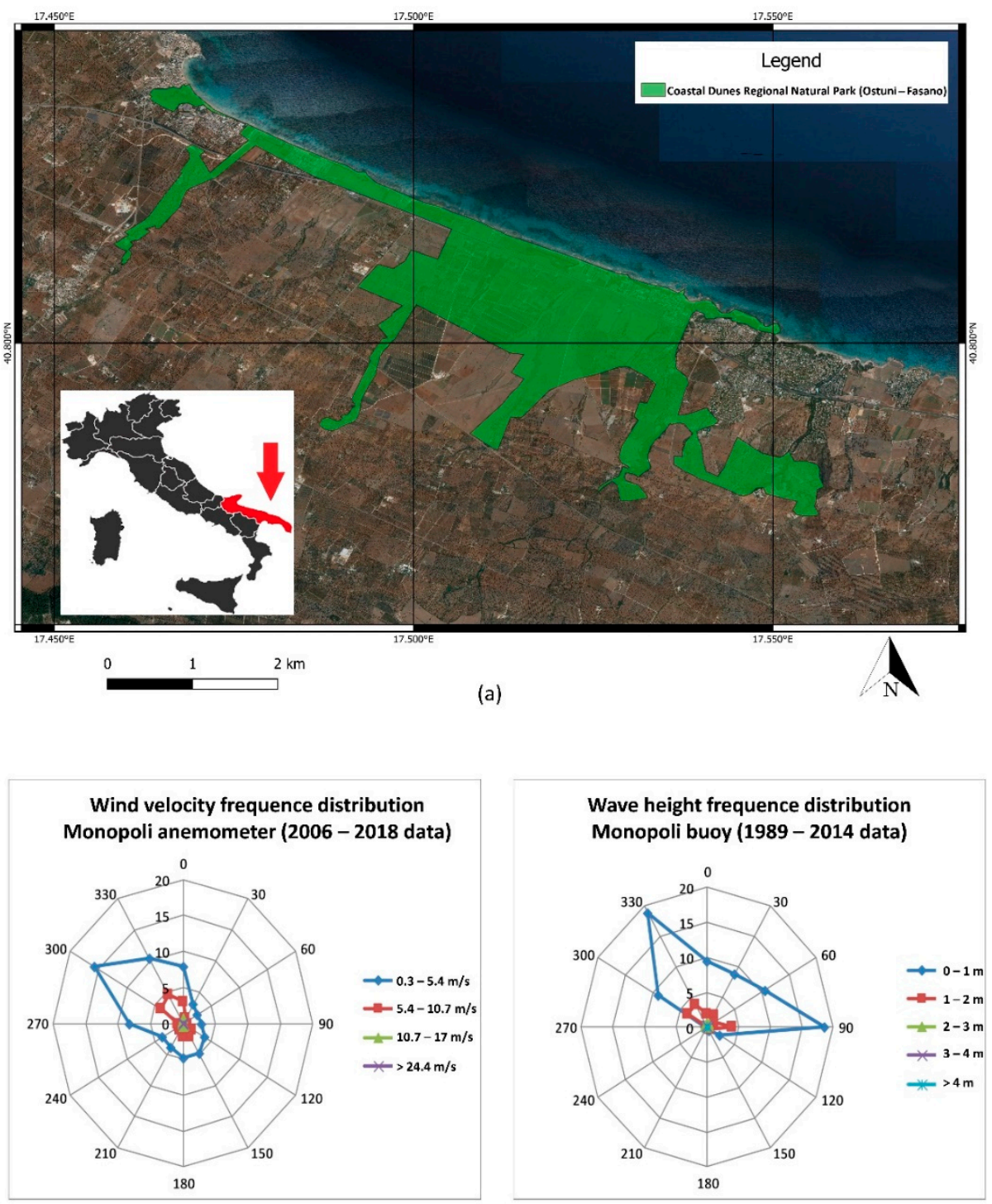

(b)

Figure 1. (a) Study area localization in the Coastal Dunes Regional Natural Park (Apulia, Italy); (b) Polar plots of the wind speed distribution and wave height distribution.

By estimating the sandy-soil surface temperature it will be possible to rapidly detect any thermal anomalies along the sandy coast, such as anomalies deriving from plastic pollution, by using thermal cameras installed on aerial or terrestrial platforms. The results 
of this study will help with the optimization of infrared thermography applications in the coastal environmental monitoring.

\subsection{Ecological Setting}

The Coastal Dunes Regional Natural Park extends from the coast towards inland agricultural areas, occupied by centuries-old olive groves. It includes the Site of Community Importance (SIC) "Litorale Brindisi", included in the European network "Natura 2000". In the Park are many species of flora that are well preserved, such as the psammophilous and Cakiletum maritimae [17-19]. The system erosion and the relative vegetation are not caused by the wind but are mainly due to people leveling the sand in the summer season, especially in the investigated site and in general on the whole psammophilous coastal area that extends from the site study and far as Brindisi.

The Park was established with the aim of conserving and recovering the habitats and animal and plant species indicated in Community Directives 79/409/EEC and 92/43/EEC.

\subsection{Geological and Geomorphological Setting}

The area covered by this study is located on the Apulian Adriatic coast, in the Coastal Dunes Park, stretched for $6 \mathrm{~km}$ from Torre Canne to Torre San Leonardo. The area hosts a coastal mobile system characterized by the presence of several lakes and ponds and by a polyphasic dune belt parallel to the coast that reaches an altitude of about $17 \mathrm{~m}$ (Figure 2).

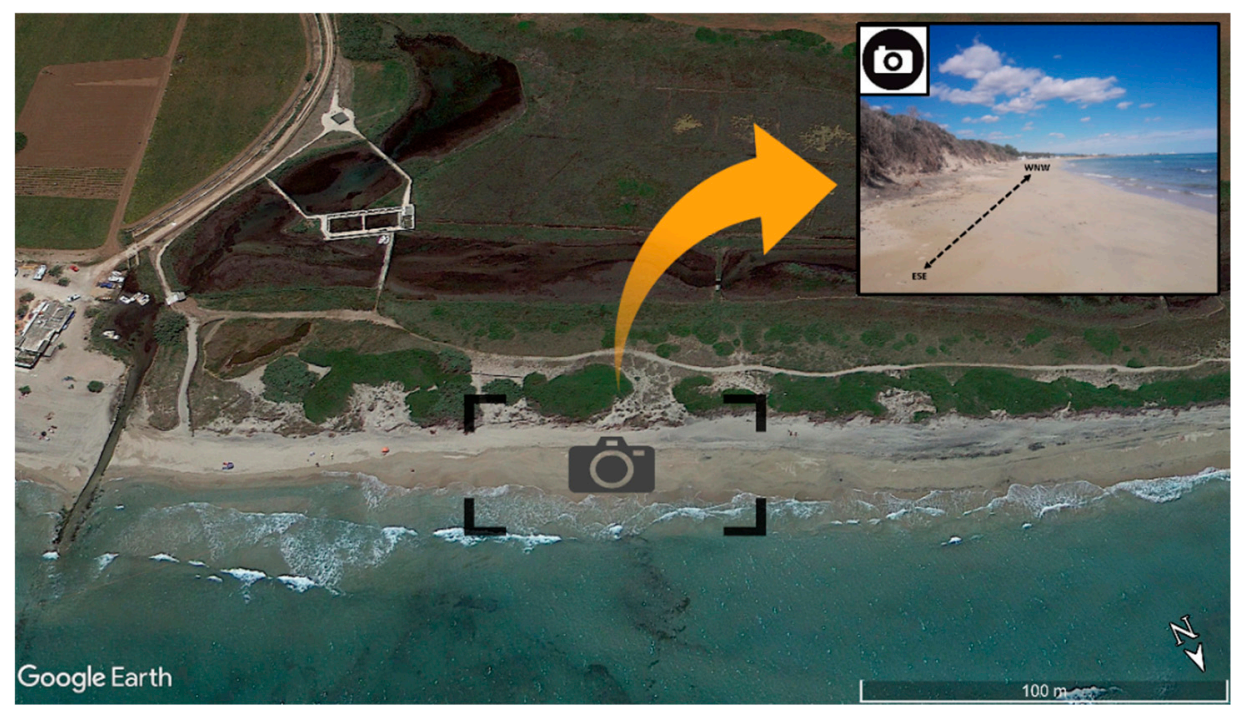

Figure 2. View of the study area (19 July 2018). The characteristics of the beach change quickly and dramatically depending on the storm surge.

The deposits consist of medium sand characterized by carbonates, quartz and other minerals in very small percentages (pyroxene and feldspar); there are also rare fragments of siliciclastic rocks and material of anthropogenic origin [20-22].

\subsection{Climatological Setting}

The average annual temperature of the study area ranges between 15 and $16{ }^{\circ} \mathrm{C}$ according to 1971-2000 monitoring data [23].

The whole coastal sector is exposed to a wind regime characterized by winds coming from the north-western quadrants (Figure 1), therefore storm surges are very frequent in winter and also cause the stranding of a large amount of natural and anthropogenic material. The main direction of the longshore transport is NW-SE [24] (Figure 1). 


\section{Materials and Methods}

In order to create a thermal blank of the beach and consequently identify the thermal polluting anomalies (attributable to the beach litter) with the thermal camera (FLIR C3), two sensors (Elitech RC-4) equipped with a data logger were installed (Figures 3 and 4). Sandy soil surface temperature data and air temperature data were collected. Soil moisture affects soil temperature just as air humidity affects air temperature. Furthermore, the humidity of the air could be influenced by other atmospheric parameters (rain, wind, atmospheric pressure) and the humidity of the sandy soil by other parameters (vegetation, storm surges, rain). Since the thermal imager acquires only the temperature data, the experimental monitoring activity concerned only the temperature data (air and soil). This was done to make the thermographic technique a methodology to support other new methodologies (spectral sensors, artificial intelligence algorithms) in emergency coastal pollution conditions where it is necessary to be quick in identification and mapping.

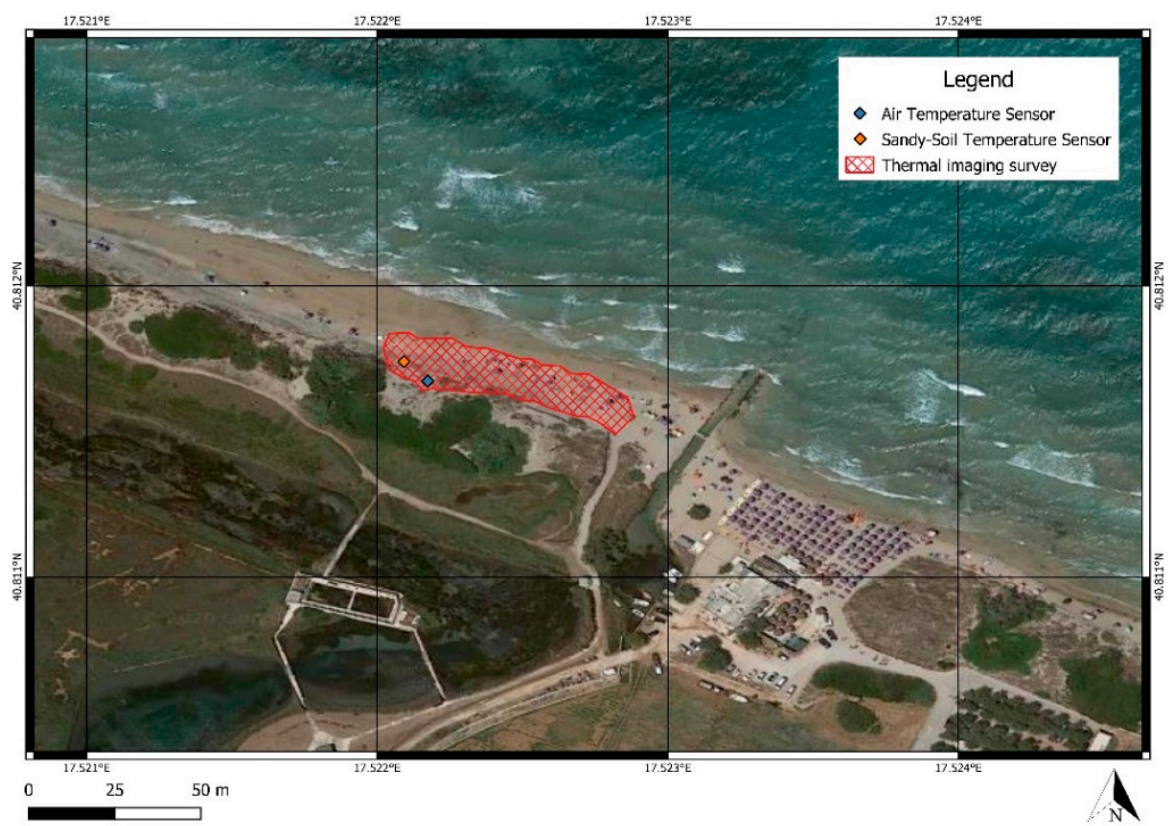

Figure 3. Sensor localization; and IR thermography survey area.

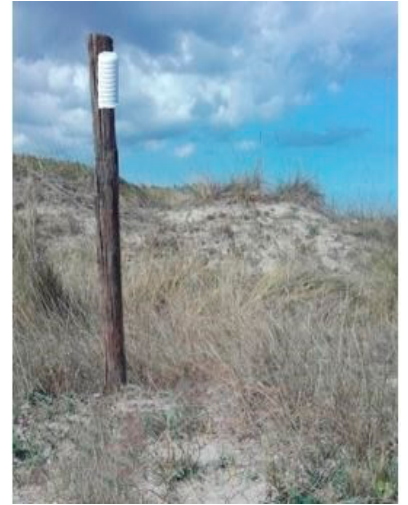

(a)

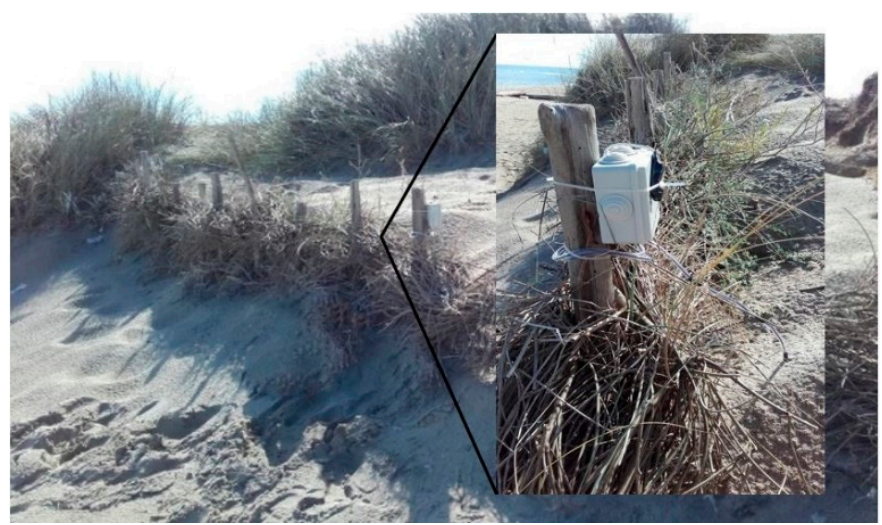

(b)

Figure 4. Air temperature sensor (a); sandy-soil surface temperature sensor (b). The pictures clearly show the presence of vegetation typical of the dune environment (Cakiletum, Ammophiletum and Agropyretum). 
The first thermal sensor inserted in a meteorological screen (solar radiation protection), was installed $2 \mathrm{~m}$ from the ground to measure air temperature (Figure 4a) as recommended by WMO (World Meteorological Organization) guidelines. The sensor is able to measure temperatures ranging from $-40{ }^{\circ} \mathrm{C}$ to $+80^{\circ} \mathrm{C}$ with a $0.1^{\circ} \mathrm{C}$ resolution and a $0.5^{\circ} \mathrm{C}$ accuracy. The Elitech RC-4 sensor with probe was used for the sandy soil surface temperature. It has the same technical specs, and the data logger was positioned on the dune into a waterproof box, protected from bad weather and anthropic interference, and the probe (connected to the data logger) directly in contact with the sandy soil surface (Figure $4 \mathrm{~b}$ ).

Both sensors were set to a sampling rate of $5 \mathrm{~min}$, the monitoring started on 7 October 2018 and ended on 15 December 2018. The monitoring period was chosen to avoid anthropogenic disturbances related to tourism, which could compromise the sensors installed. The collected data were downloaded and exported in .txt format, in a dataset gathering about 20,000 thermal data for each sensor. The statistical analysis was carried out using Microsoft Excel 2019 and R 4.0.3 software package. Daily average air and sandy-soil surface temperature was calculated, as well as Pearson's correlation coefficient. This coefficient is the test that measures the statistical relationship between two continuous variables, giving information about the correlation and the direction of the relationship, and it ranges between -1 (strong negative linear relationship) and +1 (strong positive linear relationship). A null coefficient means there is no linear relationship between the variables.

Moreover, by analysing the scatter plot, the line of best fit and the empirical equation were obtained. The coefficient of determination $\mathrm{R}^{2}$ was calculated to understand the accuracy of the regression model used to make predictions. The coefficient ranges between 0 and 1 and it is a statistical measure of how close the data are to the fitted regression line. Finally, the RMSE (Root Mean Squared Error) was calculated, and the daily average temperature values observed were compared with the ones obtained from the prediction model.

Six thermal images $80 \times 60$ (4800 pixels) on the ground were collected in the study area, using an FLIR C3 thermal imaging camera (Figure 3). Its sensor can detect and measure temperatures between $-10^{\circ} \mathrm{C}$ and $+150{ }^{\circ} \mathrm{C}$ in a spectral band ranging from 7.5 to $14 \mu \mathrm{m}$, to a resolution of $0.1^{\circ} \mathrm{C}$ and an accuracy of $\pm 2{ }^{\circ} \mathrm{C}$. The images were collected on 30 October 2018, twice in the morning (8:00 AM UTC and 9:00 AM UTC) and twice in the afternoon (12:00 PM UTC and 2:30 PM UTC); and on 31 October 31 in the morning (5:30 AM UTC) and in the afternoon (01:00 PM UTC). The observed air temperature was:

- $\quad 16.5^{\circ} \mathrm{C} \pm 0.5$ and $17.1^{\circ} \mathrm{C} \pm 0.5$ (on 30 October 2018, respectively, at 08:00 AM UTC and at 09:00 AM UTC);

- $\quad 24.8^{\circ} \mathrm{C} \pm 0.5$ and $19.5^{\circ} \mathrm{C} \pm 0.5$ (on 30 October 2018, respectively, at 12:00 PM UTC and at 02:30 PM UTC);

- $\quad 14.4^{\circ} \mathrm{C} \pm 0.5$ and $23.9^{\circ} \mathrm{C} \pm 0.5$ (on 31 October 2018, respectively, at 05:30 AM UTC and at 01:00 PM UTC).

The thermal images were processed with FLIR Tools software, setting the sand emissivity $(\varepsilon=0.90)$. For each radiometric thermal acquisition, knowing the air temperature, the empirical equation was applied in order to obtain a prediction of the sandy soil thermal range, taking into account the instrumental error.

Finally, for each thermal image processed, the GIS software created 10 random points. Later the same points were imported into the corresponding RGB images to understand what they really identified. It was assessed that the degree of confidence of the results through the calculation of the kappa coefficient $[25,26]$ allowed for the assessment of the degree of confidence of the results on a morning and afternoon scale. The kappa index measures the agreement between different assessments for the classification of the same object. Kappa index is defined as:

$$
\mathrm{K}=(\mathrm{po}-\mathrm{pe}) /(1-\mathrm{pe})
$$

po = observed agreement; pe = hypothetical probability of agreement. 
The calculation of the index is carried out with the construction of a matrix called the confusion matrix.

This index ranges from 0 to 1 and expresses the correlation between the homologues points in the IRT and RGB image. $K=1$ indicates perfect agreement while $K=0$ indicates absence of agreement. Generally, a value of the index k > 0.75 indicates a good agreement.

\section{Results and Discussion}

Daily average air temperature and sandy-soil surface temperature are shown in Figure 5, while Table 1 shows the maximum and minimum values of the daily average air temperature and sandy soil surface temperature. Figure 5 shows that the sandy-soil surface temperature is always lower than the air temperature. This happens because in the autumn the surface of the sandy soil, in this study area, is always wet.

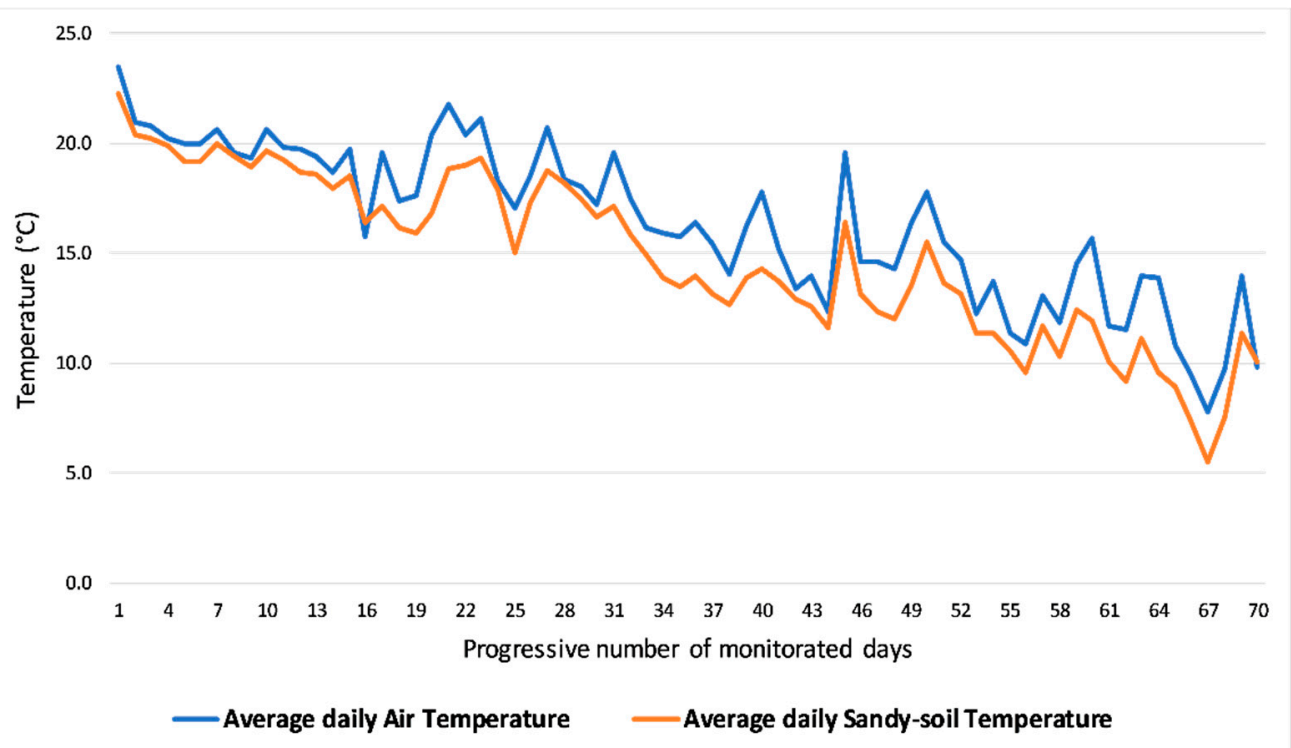

Figure 5. Daily average air and sandy soil surface temperature during the monitoring period.

Table 1. Extreme values of average temperature.

\begin{tabular}{lcc}
\hline & Air & Sandy-Soil Surface \\
\hline Maximum daily average temperature $\left({ }^{\circ} \mathrm{C}\right)$ & 23.5 & 22.2 \\
Minimum daily average temperature $\left({ }^{\circ} \mathrm{C}\right)$ & 7.8 & 5.5 \\
\hline
\end{tabular}

The Pearson correlation coefficient shows a strong positive correlation (0.97) between average daily air temperature and average daily sandy-soil surface temperature soil. The best model for the study area, approximating the empirical data, was calculated from the scatter plot (Figure 6) and it results in a non-linear regression, a power function. In fact, in the interpolation curve, a slight upwards concavity can be observed. 


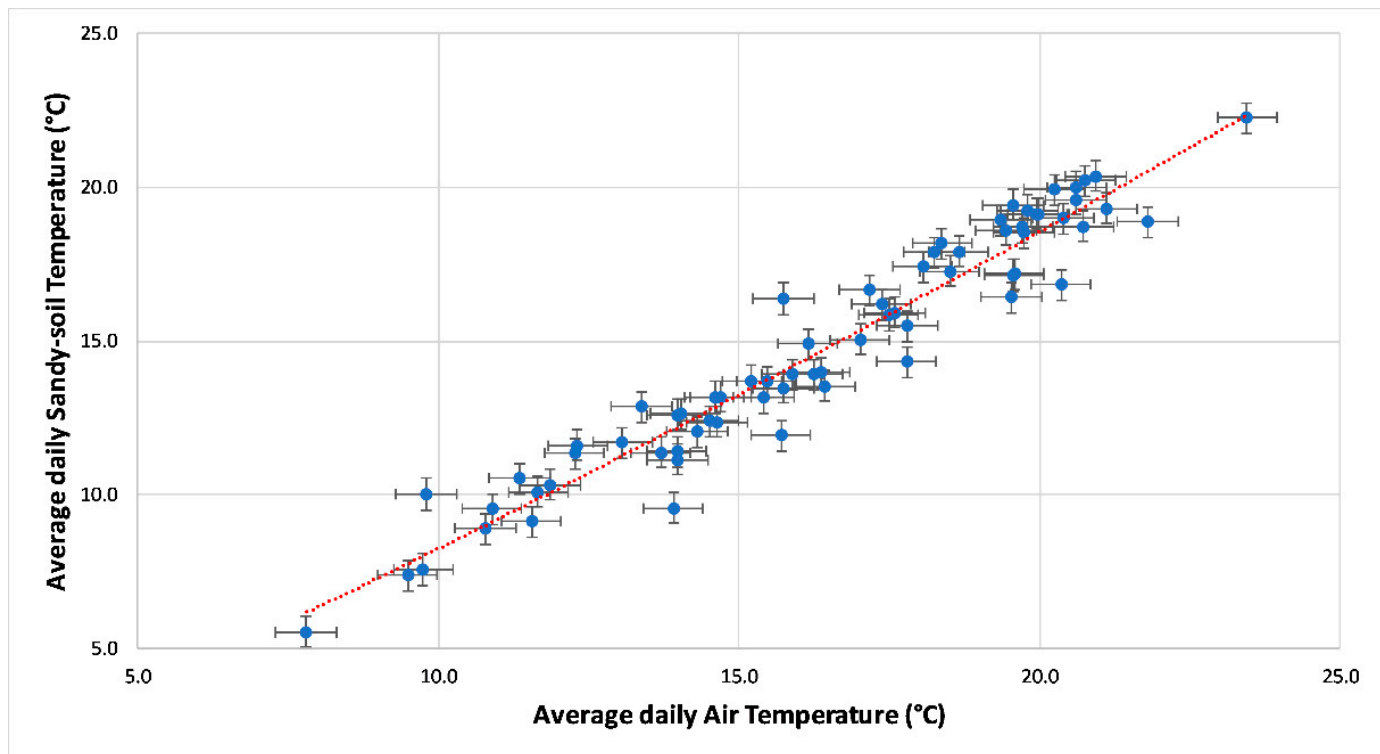

Figure 6. Scatter plot between average air temperature and sandy soil surface temperature.

The resulting model is represented by the equation:

$$
\mathrm{Ts}=0.5572 \times \mathrm{Ta}^{1.1701}
$$

Ts = sandy-soil surface temperature; Ta = air temperature

The coefficient of determination $\mathrm{R}^{2}=0.94$ has validated the statistical model. The empirical equation obtained was used to predict the daily average sandy-soil surface temperature knowing the air temperature. Therefore, the results were compared with the temperature measured on site (Figure 7).

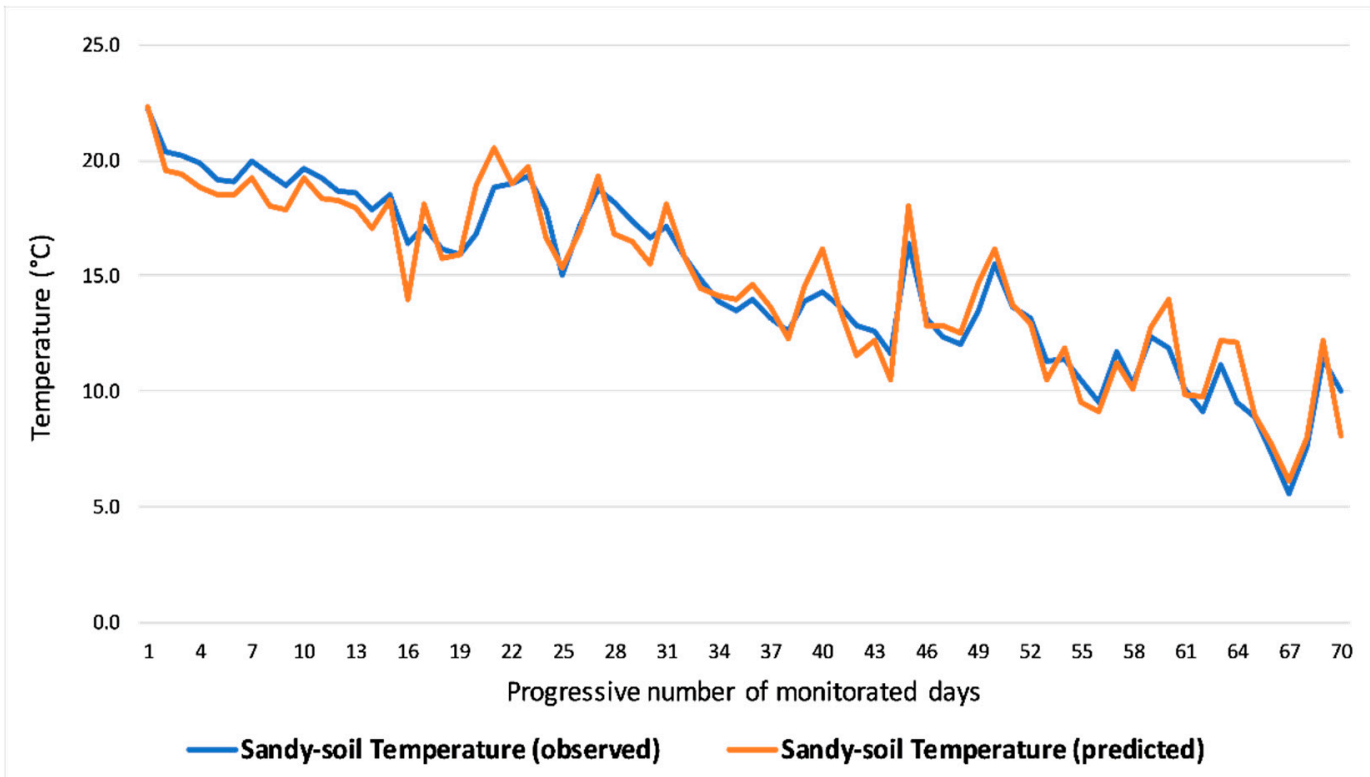

Figure 7. Comparison between measured and predicted sandy soil surface temperature during the same monitoring period.

RMSE has been obtained through statistical processing. It is a statistical indicator that quantifies the deviation between the observed and simulated data. The value of RMSE stood at 0.96 . The very low value confirms the accuracy of the empirical equation obtained. For statistical completeness, a linear regression of the data was also performed. Although 
the value of $R^{2}=0.94$ was equal to the non-linear regression, the value of the RMSE (0.97) was slightly higher than the non-linear regression. This statistical difference influenced the choice of the regression typology to obtain the empirical equation.

Table 2 shows the air temperature values obtained from the morning and afternoon thermal imaging survey. Sandy-soil surface temperature values was obtained by using these values in the Equation (2). Moreover, taking into account the thermal camera accuracy, the thermal range of the sandy soil surface is shown.

Table 2. Temperature data (30-31 October 2018).

\begin{tabular}{cccc}
\hline & Air Temp. $\left({ }^{\circ} \mathbf{C}\right)$ Observed & $\begin{array}{c}\text { Sandy Soil Surface Temp. }\left({ }^{\circ} \mathrm{C}\right) \\
\text { Predicted by Applying (2) }\end{array}$ & $\begin{array}{c}\text { Potential Thermal Range of Sandy Soil } \\
\text { Surface (for Each IR Image) Considering } \\
\text { the Previous Column and the Instrumental } \\
\text { Accuracy }\left( \pm \mathbf{2}{ }^{\circ} \mathbf{C}\right)\end{array}$ \\
\hline 08:00 AM UTC & 16.5 & 14.8 & $12.8-16.8$ \\
09:00 AM UTC & 17.1 & 15.5 & $13.5-17.5$ \\
12:00 PM UTC & 24.8 & 20.5 & $18.5-22.5$ \\
02:30 PM UTC & 19.5 & 18 & $16-20$ \\
05:30 AM UTC & 14.4 & 12.6 & $10.6-14.6$ \\
01:00 PM UTC & 23.9 & 22.8 & $20.8-24.8$ \\
\hline
\end{tabular}

Figure 8 shows the thermal images collected in the morning of 30 October 2018 and 31 October 2018, processed using FLIR Tools. Table 3 shows the correspondence of the material detected in the thermal image (prediction) compared with the RGB image (truth) in the randomly selected points.

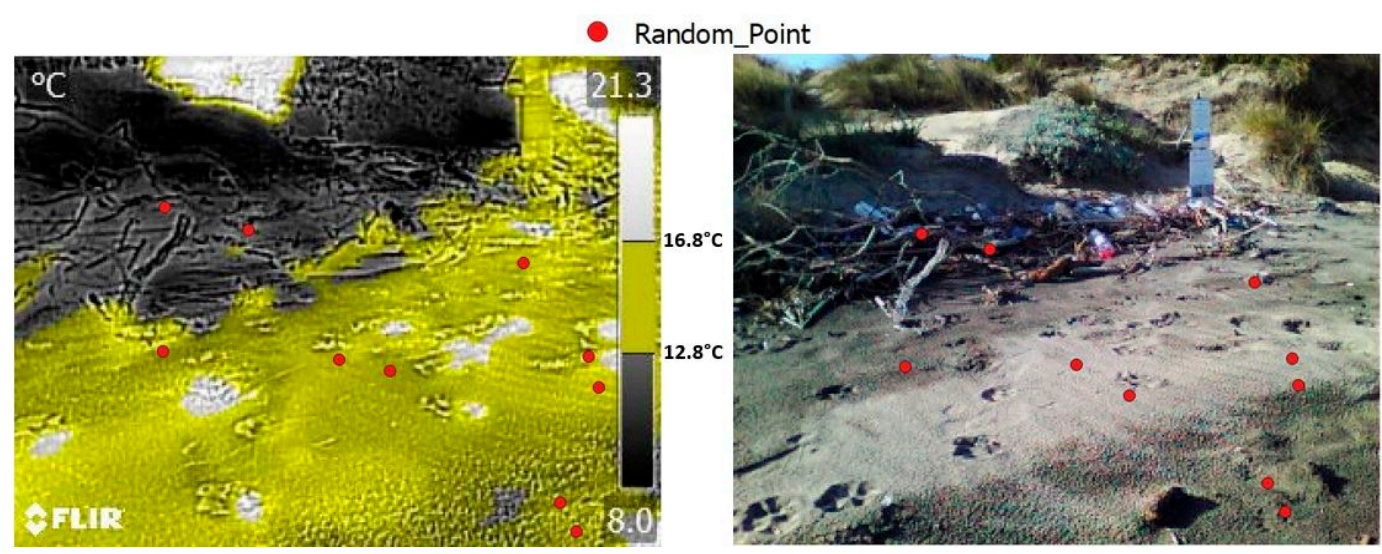

(a)

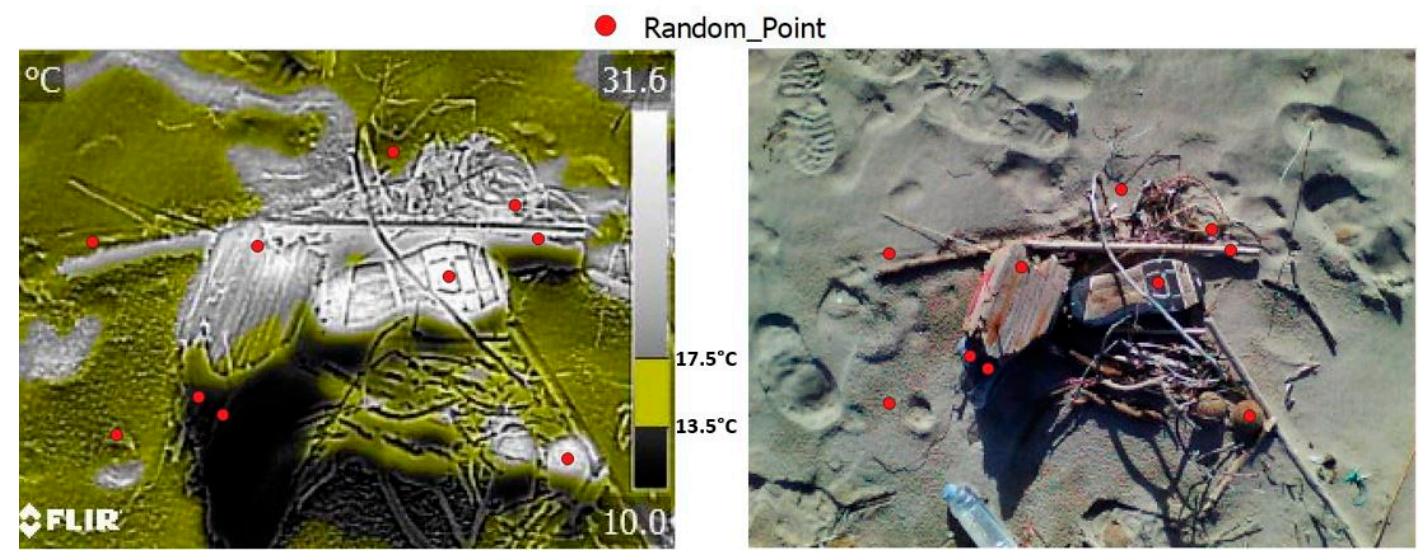

(b)

Figure 8. Cont. 


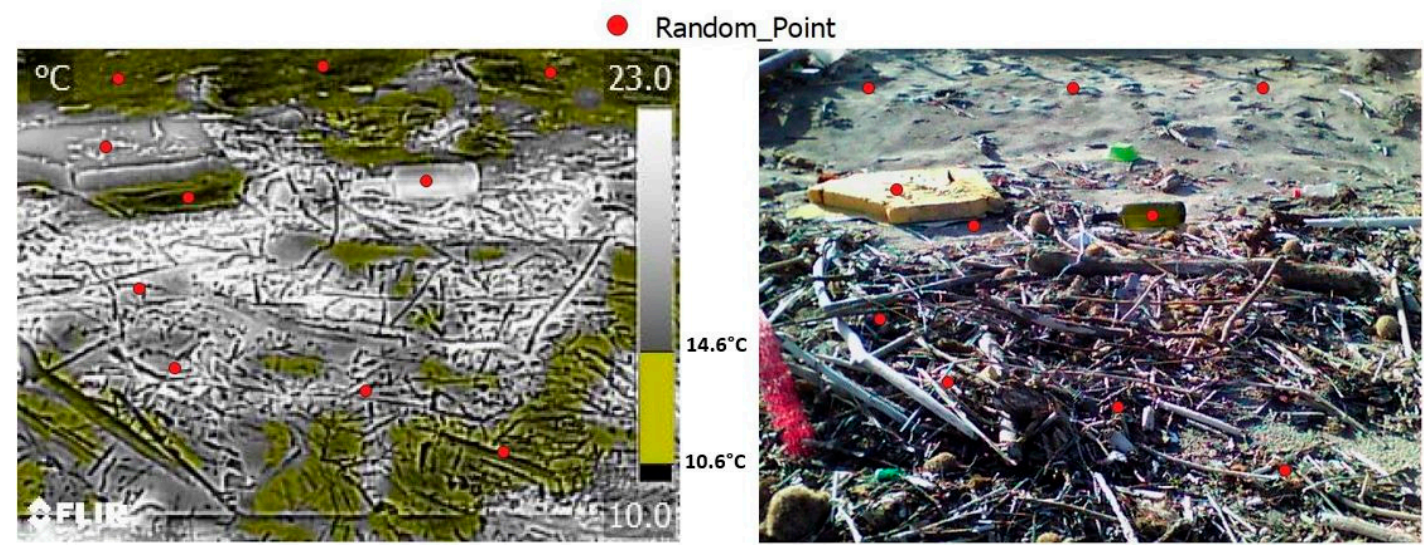

(c)

Figure 8. Morning acquisition: thermal image (on the left) and RGB image (on the right). Randomly selected points (in red). The yellow pixels in the thermal image indicate the sandy soil surface identified by the application of the empirical Equation (2). Plastic bottles can be seen in (a), rubber soles in (b), glass bottles and expanded polystyrene in (c).

Table 3. Correspondence between the material detected in the thermal image and the RGB image in the selected points (morning).

\begin{tabular}{ccccc}
\hline & & Material in the RGB Image (Truth) \\
\hline & & Sandy Soil & $\begin{array}{c}\text { Natural and/or Anthropic } \\
\text { Anomaly }\end{array}$ & Total \\
\hline $\begin{array}{c}\text { Material detected in the } \\
\text { thermal image } \\
\text { (prediction) }\end{array}$ & Sandy soil & 15 & 1 & 16 \\
\hline
\end{tabular}

The kappa coefficient value was calculated and resulted to be equal to 0.93. Figure 9 shows the thermal images collected in the afternoon of 30 October 2018 and 31 October 2018 and processed. Table 4 shows the correspondence between of the material detected in the thermal image (prediction) compared with the RGB image (truth) in 30 random points.

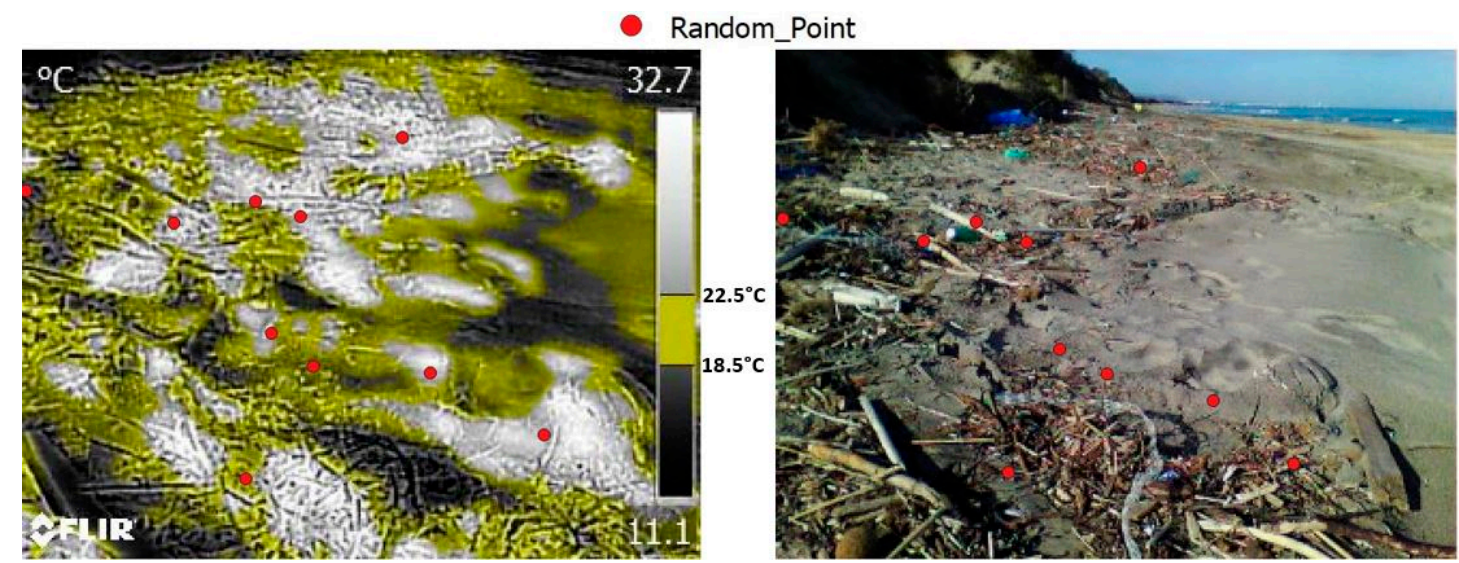

(a)

Figure 9. Cont. 


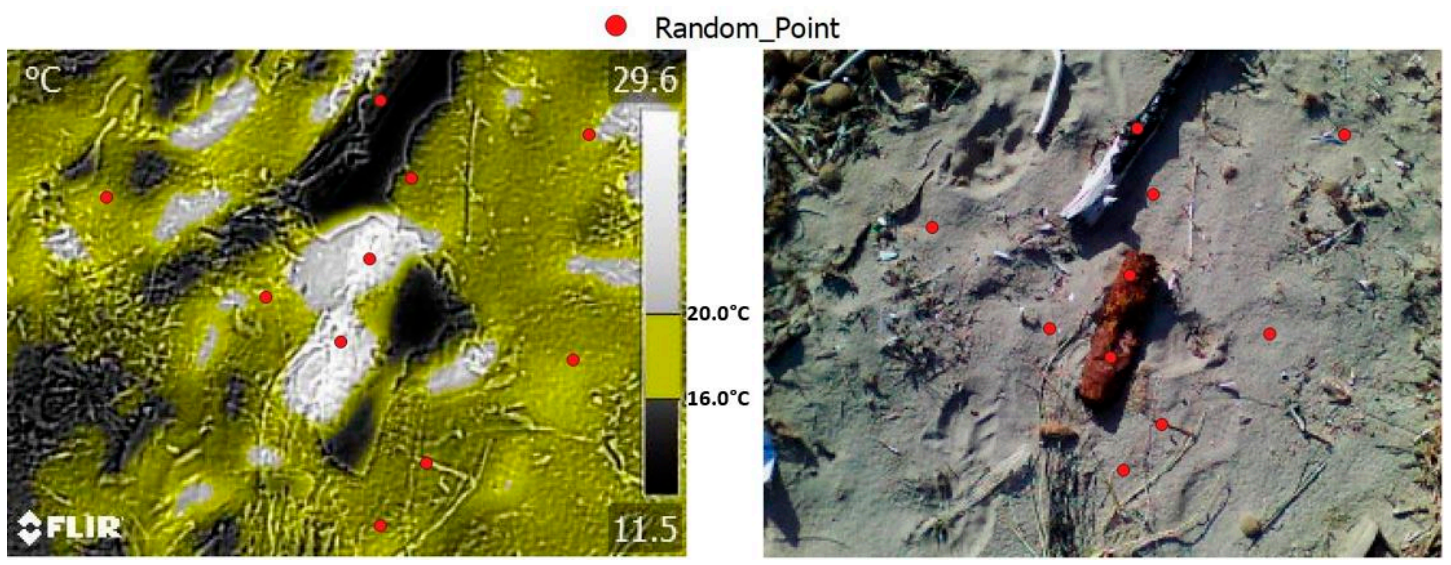

(b)

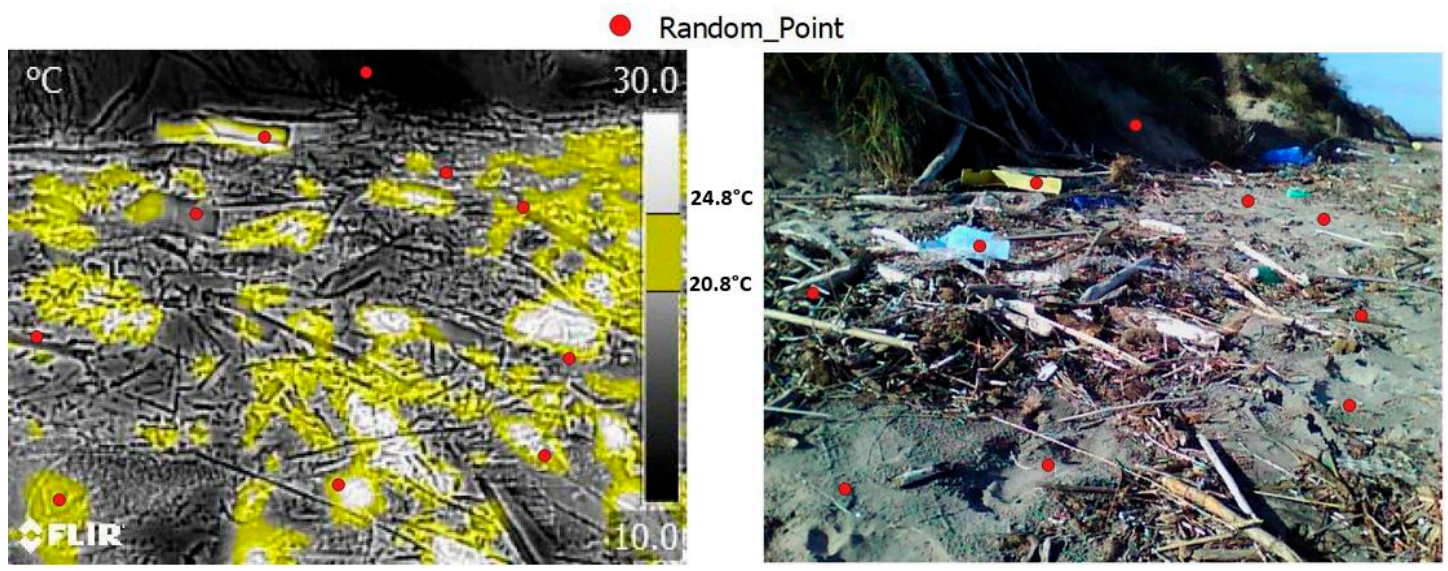

(c)

Figure 9. Afternoon acquisition: thermal image (on the left) and RGB image (on the right). Randomly selected points (in red). The yellow pixels in the thermal image represent the sandy soil surface identified by the application of the empirical Equation (2). Plastic bottles and bags can be seen in $(\mathbf{a}, \mathbf{c})$ and rusty bottles in (b).

Table 4. Correspondence between the material detected in the thermal image and the RGB image in the selected points (afternoon).

\begin{tabular}{|c|c|c|c|c|}
\hline & & \multicolumn{3}{|c|}{ Material in the RGB Image (Truth) } \\
\hline & & Sandy Soil & $\begin{array}{l}\text { Natural and/or Anthropic } \\
\text { Anomaly }\end{array}$ & Total \\
\hline Material detected in the & Sandy soil & 13 & 1 & 14 \\
\hline thermal image & Natural and/or anthropic anomaly & 3 & 13 & 16 \\
\hline (prediction) & Total & 16 & 14 & 30 \\
\hline
\end{tabular}

The kappa coefficient value was calculated and resulted to be equal to 0.74 . The results obtained from empirical equation application in the thermal images, the comparison between the material detected in the thermal images and the values of the kappa coefficient, allowed for validation of the thermal methodology used, which was developed to identify sandy soil on the coast using IR thermography, distinguishing it from thermal anomalies which can be due to the presence of different materials and polluting objects and material of anthropogenic origin such as plastic. The methodology described may have problems with shaded areas, because they are significantly cooler than the predicted soil temperature value. However, using UAV systems with larger scale acquisitions, the shaded areas would have less weight in the acquired thermograms than the really radiated beach areas. 


\section{Conclusions}

This study represents an application of the IR thermography technology in the field of coastal environmental monitoring. The 70-day monitoring of the air and sandy soil surface temperature by means of two thermal sensors, carried out in the Coastal Dunes Regional Natural Park (Ostuni-Fasano), and the statistical analysis of a considerable amount of thermal data, allowed the development of an empirical equation used for calculating the sandy-soil surface temperature by knowing only the air temperature. The existence of a strong correlation between the two variables, the high value of the coefficient of determination $R^{2}$ of the model and a low value of the RMSE value, confirmed the good quality of the empirical equation used.

Moreover, the tests carried out applying the equation to the IR thermal survey and the value of the kappa coefficient calculated, validated this methodology, making it an effective tool for anthropogenic polluting material detection (plastic, glass, rubber) on the sandy coast in the study area.

The results obtained can be used to rapidly process thermal images deriving from surveys carried out with sensors installed on UAV and UGV, quickly detecting the presence of anomalies due to potentially polluting objects (like plastic, glass, etc) or other pollutant materials.

Further coastal environmental geology studies will be carried out in the future. In particular, remote multispectral methodologies will be tested in this study area for a more precise identification of pollutants.

Author Contributions: Conceptualization (C.C.), Data curation (C.C.), Formal analysis (C.C.; E.P. and S.R.), Founding acquisition (S.R. and G.M.), Investigation (C.C. and E.P.), Methodology (C.C.), Project administration (G.M.), Resources (S.R. and G.M.), Software (C.C.), Supervision (H.R.; S.R. and G.M.), Validation (C.C.; E.P.; S.R. and G.M.), Visualization (C.C. and E.P.), Writing-original draft (C.C. and E.P.), Writing-review and editing (C.C.; E.P.; S.R. and G.M.). All authors have read and agreed to the published version of the manuscript.

Funding: Contributo Protezione Civile Regione Puglia-Progetto I-STORMS; Scientific Supervisor: Giuseppe Mastronuzzi.

Institutional Review Board Statement: Not applicable.

Informed Consent Statement: Not applicable.

Data Availability Statement: The data presented in this study are available on request from the corresponding author.

Acknowledgments: The authors would like to thank the reviewers for their contributions and constructive comments for the improvement of the manuscript and Regional Natural Park of the Coastal Dunes for their kind support. Work carried out as part of the research project "SIATIntegrated UAV-UTV system with remote control for the pollutants dispersion assessment in the coastal environment for remediation" related to the XXXIII PON Cycle of the Ph.D. in Geosciences of the University of Bari, under the responsibility of Massimo Moretti.

Conflicts of Interest: The authors declare no conflict of interest.

\section{References}

1. Bianchi, F.; Pisello, A.L.; Baldinelli, G.; Asdrubali, F. Infrared Thermography Assessment of Thermal Bridges in Building Envelope: Experimental Validation in a Test Room Setup. Sustainability 2014, 6, 7107-7120. [CrossRef]

2. Costanzo, A.; Minasi, M.; Casula, G.; Musacchio, M.; Buongiorno, M.F. Combined Use of Terrestrial Laser Scanning and IR Thermography Applied to a Historical Building. Sensors 2015, 15, 194-213. [CrossRef] [PubMed]

3. Garduño-Ramón, M.A.; Vega-Mancilla, S.G.; Morales-Henández, L.A.; Osornio-Rios, R.A. Supportive Noninvasive Tool for the Diagnosis of Breast Cancer Using a Thermographic Camera as Sensor. Sensors 2017, 17, 497. [CrossRef] [PubMed]

4. Kim, J. Non-Destructive Characterization of Railway Materials and Components with Infrared Thermography Technique. Materials 2019, 12, 4077. [CrossRef] [PubMed]

5. Aranda, J.M.; Melendez, J.; De Castro, A.J.; Lopez, F. Forest fire studies by medium infrared and thermal infrared thermography. In Proceedings of the Thermosense XXIII, Orlando, FL, USA, 23 March 2001; Volume 4360. 
6. Cagnazzo, C.; Potente, E.; Rosato, S.; Mastronuzzi, G. Geostatistics and Structure from Motion Techniques for Coastal Pollution Assessment along the Policoro Coast (Southern Italy). Geosciences 2020, 10, 28. [CrossRef]

7. Cagnazzo, C.; Potente, E.; Rosato, S.; Mastronuzzi, G. Numerical modeling for coastal environmental monitoring: Oil spills simulation along the lower Adriatic coasts. Rend. Online Soc. Geol. It. 2020, 52, 19-24. [CrossRef]

8. Manfreda, S.; McCabe, M.F.; Miller, P.E.; Lucas, R.; Pajuelo Madrigal, V.; Mallinis, G.; Ben Dor, E.; Helman, D.; Estes, L.; Ciraolo, G.; et al. On the Use of Unmanned Aerial Systems for Environmental Monitoring. Remote Sens. 2018, 10, 641. [CrossRef]

9. Stuart, M.B.; McGonigle, A.J.S.; Willmott, J.R. Hyperspectral Imaging in Environmental Monitoring: A Review of Recent Developments and Technological Advances in Compact Field Deployable Systems. Sensors 2019, 19, 3071. [CrossRef] [PubMed]

10. Zanutta, A.; Lambertini, A.; Vittuari, L. UAV Photogrammetry and Ground Surveys as a Mapping Tool for Quickly Monitoring Shoreline and Beach Changes. J. Mar. Sci. Eng. 2020, 8, 52. [CrossRef]

11. Casana, J.; Kantner, J.; Wiewel, A.; Cothren, J. Archaeological aerial thermography: A case study at the Chaco-era Blue J community, New Mexico. J. Archaeol. Sci. 2014, 45, 207-219. [CrossRef]

12. Lega, M.; Kosmatka, J.; Ferrara, C.; Russo, F.; Napoli, R.M.A.; Persechino, G. Using Advanced Aerial Platforms and Infrared Thermography to Track Environmental Contamination. Environ. Forensics J. 2012, 13, 332-338. [CrossRef]

13. Lagüela, S.; Díaz-Vilariño, L.; Roca, D.; Lorenzo, H. Aerial thermography from low-cost UAV for the generation of thermographic digital terrain models. Opto-Electron. Rev. 2015, 23, 78-84. [CrossRef]

14. Ficapal, A.; Mutis, I. Framework for the Detection, Diagnosis, and Evaluation of Thermal Bridges Using Infrared Thermography and Unmanned Aerial Vehicles. Buildings 2019, 9, 179. [CrossRef]

15. Savelyev, A.; Sugumaran, R. Surface Temperature Mapping of the University of Northern Iowa Campus Using High Resolution Thermal Infrared Aerial Imageries. Sensors 2008, 8, 5055-5068. [CrossRef] [PubMed]

16. Szrek, J.; Wodecki, J.; Błażej, R.; Zimroz, R. An Inspection Robot for Belt Conveyor Maintenance in Underground Mine--Infrared Thermography for Overheated Idlers Detection. Appl. Sci. 2020, 10, 4984. [CrossRef]

17. Ciola, G.; Maiorano, F.; Massari, M.A. Il Parco Naturale Regionale delle Dune Costiere da Torre Canne a Torre San Leonardo: Il valore della biodiversità per ricostruire comunità solidali. Territori e comunità. In Le sfide dell'autogoverno comunitario. Atti dei Laboratori del VI Convegno della Società dei Territorialisti Castel del Monte (BA); Gisotti, M.R., Rossi, M., Eds.; Sdt Edizioni: Bari, Italy, 2018.

18. Perrino, E.V.; Ladisa, G.; Calabrese, G. Flora and plant genetic resources of ancient olive groves of Apulia (southern Italy). Genet. Resour. Crop Evol. 2014, 61, 23-53. [CrossRef]

19. Tomaselli, V.; Tenerelli, P.; Sciandrello, S. Mapping and quantifying habitat fragmentation in small coastal areas: A case study of three protected wetlands in Apulia (Italy). Monit. Assess. 2012, 184, 693-713. [CrossRef]

20. Mastronuzzi, G.; Palmentola, G.; Sanso, P. Evoluzione morfologica della fascia costiera di Torre Canne (Puglia adriatica). Studi Costieri 2001, 4, 19-31.

21. Mastronuzzi, G.; Sanso, P. Holocene coastal dune development and environmental changes in Apulia (Southern Italy). Sediment. Geol. 2002, 150, 139-152. [CrossRef]

22. Moretti, M.; Tropeano, M.; Van Loon, A.J.; Acquafredda, P.; Baldacconi, R.; Festa, V.; Lisco, S.; Mastronuzzi, G.; Moretti, V.; Scotti, $\mathrm{R}$. Texture and composition of the Rosa Marina beach sands (Adriatic coast, southern Italy): A sedimentological/ecological approach. Geologos 2016, 22, 87-103. [CrossRef]

23. Marsico, A.; Caldara, M.; Capolongo, D.; Pennetta, L. Climatic characteristics of middle-southern Apulia (southern Italy). J. Maps 2007, 3, 342-348. [CrossRef]

24. Mastronuzzi, G.; Palmentola, G.; Sansò, P. Lineamenti e dinamica della costa pugliese. Studi Costieri 2002, 5, 9-22.

25. Cohen, J. A coefficient of agreement for nominal scales. Educ. Psychol. Meas. 1960, 20, 37-46. [CrossRef]

26. Cohen, J. Weighed kappa: Nominal scale agreement with provision for scaled disagreement or partial credit. Psychol. Bulletin. 1968, 70, 213-220. [CrossRef] [PubMed] 